Gut and Liver, Vol. 11, No. 4, July 2017, pp. 464-473

\title{
Ultrasonography for Noninvasive Assessment of Portal Hypertension
}

\author{
Hitoshi Maruyama and Osamu Yokosuka \\ Department of Gastroenterology and Nephrology, Chiba University Graduate School of Medicine, Chiba, Japan
}

Portal hypertension is a major pathophysiology in patients with cirrhosis. Portal pressure is the gold standard to evaluate the severity of portal hypertension, and radiological intervention is the only procedure for pressure measurement. Ultrasound (US) is a simple and noninvasive imaging modality available worldwide. B-mode imaging allows broad applications for patients to detect and characterize chronic liver diseases and focal hepatic lesions. The Doppler technique offers real-time observation of blood flow with qualitative and quantitative assessments, and the application of microbubble-based contrast agents has improved the detectability of peripheral blood flow. In addition, elastography for the liver and spleen covers a wider field beyond the original purpose of fibrosis assessment. These developments enhance the practical use of US in the evaluation of portal hemodynamic abnormalities. This article reviews the recent progress of US in the assessment of portal hypertension. (Gut Liver 2017;11:464-473)

Key Words: Ultrasonography, Doppler; Contrast media; Liver; Hypertension, portal

\section{INTRODUCTION}

Because of the close relationship with disease severity, portal hemodynamics is the key pathophysiology in cirrhosis. ${ }^{1-3}$ The development of collateral vessels represents a portal abnormality, which results in gastroesophageal varices, ectopic varices, and hepatic encephalopathy; these are the major manifestations in cirrhosis. ${ }^{4-6}$ A proper management may be the key issue in clinical practice because the complications caused by portal hypertension affect the prognosis and quality of life of cirrhosis patients. $^{7,8}$

The severity of portal hypertension is determined by the por- tal pressure. ${ }^{7,9}$ Performing interventional radiology (IVR) may be the only procedure to obtain the hepatic venous pressure gradient (HVPG), a surrogate marker for directly measured portal pressure. However, because of its invasiveness under radiation exposure, noninvasive markers available for repeated use during the long-term clinical course may be preferable., ${ }^{1,10}$

Because of simple and less-invasive evaluations, ultrasound (US) may be the most frequently used imaging procedure in the practical management of patients with chronic liver disease. ${ }^{4,5}$ Doppler mode enables real-time observation of blood flow under physiological conditions, and contrast-enhanced US with microbubble contrast agents allows detailed assessment of peripheral blood flow. In addition, elastography for liver and spleen shows broad application beyond the original purpose of fibrosis assessment. Clearly, such advancement is supported by the development of digital technologies and diffusion of information. With this background, this review article describes the recent progress of using US in the noninvasive assessment of portal hypertension.

\section{B-MODE US}

Recent developments in digital technology have introduced various imaging modes, color/power Doppler, harmonic imaging for contrast enhancement, three-dimensional visualization, and fusion imaging. ${ }^{1,411}$ However, fundamental tissue images are available only using B-mode sonography. The role of this simple technique for portal hypertension is to characterize cirrhosis, measure vessel diameter and spleen size, and identify the ascites and abnormal collateral route. ${ }^{12-14}$ However, because they are indirect findings to suspect the presence of portal hypertension, benefits of B-mode US on the prediction of portal pressure and the assessment of the severity of portal hypertension are limited.

\footnotetext{
Correspondence to: Hitoshi Maruyama

Department of Gastroenterology and Nephrology, Chiba University Graduate School of Medicine, 1-8-1 Inohana, Chuo-ku, Chiba 260-8670, Japan Tel: +81-43-2262083, Fax: +81-43-2262088, E-mail: maru-cib@umin.ac.jp

Received on February 11, 2016. Revised on June 7, 2016. Accepted on June 18, 2016. Published online March 9, 2017

pISSN 1976-2283 eISSN 2005-1212 https://doi.org/10.5009/gnl16078

(a) This is an Open Access article distributed under the terms of the Creative Commons Attribution Non-Commercial License (http://creativecommons.org/licenses/by-nc/4.0) which permits unrestricted non-commercial use, distribution, and reproduction in any medium, provided the original work is properly cited.
} 


\section{DOPPLER US}

With the advantage of real-time observation of blood flow under physiological conditions, studies using Doppler US have been performed for evaluating the severity of liver disease and portal hypertension (Fig. 1). ${ }^{1,4,6,15-18}$ Indeed, portal hemodynamics are predictive markers of outcomes in cirrhosis, lower velocity $(<12.8 \mathrm{~cm} / \mathrm{s})$ in the portal trunk in compensated cirrhosis for decompensation, and reverse portal flow in decompensated cirrhosis for poor prognosis (Table 1$).{ }^{19}$ However, a major issue is the prediction of HVPG, which is a standard maker for the severity of portal hypertension. According to a Korean study, patients with a damping index (minimum velocity/maximum velocity of the hepatic vein waveform) $>0.6$ are significantly more likely to have severe portal hypertension (SPH; HVPG >12 $\mathrm{mm} \mathrm{Hg}$ ), with 76\% sensitivity and $82 \%$ specificity, suggesting

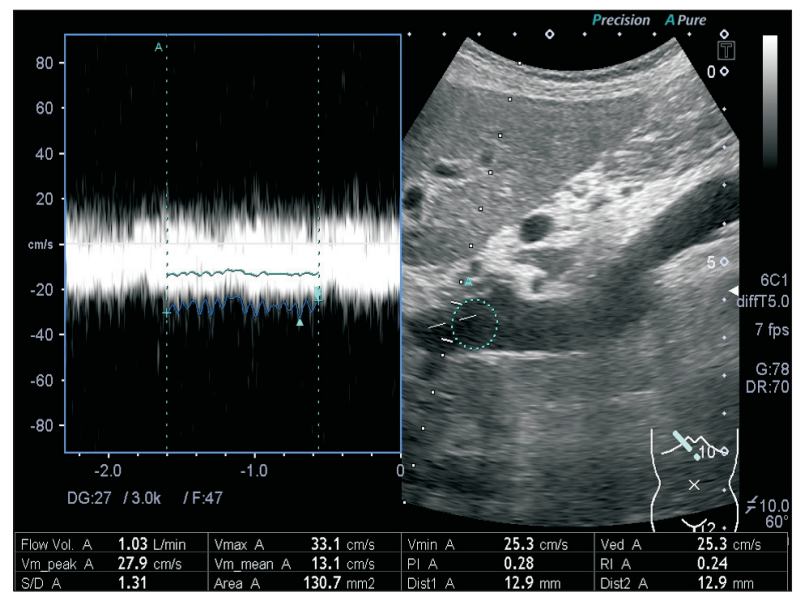

Fig. 1. Pulsed Doppler image for portal trunk (68-year-old male, non$\mathrm{B}$, non-C cirrhosis). The portal trunk was demonstrated as a longitudinal view and sample volume was used with the optimal width to include the vessel. Time-averaged mean flow velocity was obtained from the waveform of the Doppler signal with the beam-vessel angle, which was 60 degrees or smaller. Flow volume was calculated by multiplying mean flow velocity by automatic cross-section of the vessel every 60 seconds. an effective parameter to predict the grade of portal hypertension (Table 1). ${ }^{20}$ In another study, in 66 patients with hepatitis $\mathrm{C}$ virus infection, there were significant correlations between HVPG and intraparenchymal splenic artery resistance index (SA-RI) ( $\mathrm{r}=0.50, \mathrm{p}<0.0001)$, superior mesenteric artery-pulsatility index (SMA-PI) $(r=-0,48, p<0.0001)$, and right interlobar renal artery resistance index (RRA-RI) $(\mathrm{r}=0.51, \mathrm{p}<0.0001)$ (Table 1). ${ }^{21}$ However, dividing patients according to the presence or absence of SPH, correlations between HVPG and intraparenchymal SA$\mathrm{RI}(\mathrm{r}=0.70, \mathrm{p}<0.0001)$, SMA-PI $(\mathrm{r}=-0.49, \mathrm{p}=0.02)$, and RRA-RI $(r=0.66, p=0.0002)$ were observed only in patients with HVPG $<12 \mathrm{~mm} \mathrm{Hg}$. The HVPG but not Doppler parameters correlated with the presence of esophageal varices (EV; $p<0.0001)$. Indeed, the negative aspect of the Doppler US may be enhanced in late years because of less statistical power for the prediction of clinically significant portal hypertension (CSPH; HVPG >10 mm $\mathrm{Hg}$ ) and EV. ${ }^{22}$ The effect of Doppler US to predict the severity of portal hypertension may still be debated due to the lack of a definitive parameter.

\section{CONTRAST-ENHANCED US}

\section{Contrast-enhanced US and portal hypertension}

With its simplicity and safety, contrast-enhanced US has become popular for assessing liver disease. ${ }^{23-26}$ Currently, it is applied in the wide range of liver diseases to differentiate diffuse liver diseases and assess the severity of portal hypertension, in addition to the management of focal hepatic lesions. ${ }^{4-11}$

The interval time between vessels is a representative parameter for microbubble hemodynamics and shows close correlation with portal pressure, between free portal pressure and hepatic vein-hepatic artery interval time $(r=-0.804, p=0.009)$ or the portal vein-hepatic artery interval time $(r=0.506, p=0.036) .{ }^{27}$ More recent studies have demonstrated original parameters for portal pressure; the first study proposed "regional hepatic perfusion" using SonoVue, which correlated with HVPG ( $r=0.279, p=0.041)$ and hyperdynamic syndrome markers. ${ }^{28}$ The other study has shown that the portal vein/hepatic artery time-intensity curve

Table 1. Diagnostic Ability of Doppler Parameters

\begin{tabular}{cccccccc}
\hline \multicolumn{1}{c}{ Study } & Patients, no. & Etiology & \multicolumn{1}{c}{ Parameter } & Cutoff value & Diagnosis & Se/Sp/PPV/NPV & AUROC \\
\hline Kondo et al. $^{19}$ & 236 & Mix & Velocity & $12.8 \mathrm{~cm} / \mathrm{s}$ & Decompensation & $68 / 75 / 68 / 75$ & 0.7395 \\
& & & Flow direction & Reverse & Prognosis & $21.8 / 99.3 / 70.6 / 60.6$ \\
Kim et al. $^{20}$ & 76 & Mix & Damping index* & 0.6 & SPH & $75.9 / 81.8 / 91.1 / 58.1$ & 0.860 \\
Vizzutti et al. $^{21}$ & 66 & HCV & SA-RI & 0.6 & SPH & $84.6 / 70.4 / 80 / 76$ & 0.82 \\
& & & SMA-PI & 2.7 & SPH & $85.7 / 65.2 / 79 / 75$ & 0.78 \\
& & & RRA-RI & 0.65 & SPH & $79.5 / 59.3 / 74 / 66$ & 0.78 \\
\hline
\end{tabular}

Se, sensitivity; Sp, specificity; PPV, positive predictive value; NPV, negative predictive value; AUROC, area under the receiver operating curve; $\mathrm{SPH}$, severe portal hypertension (hepatic venous pressure gradient $>12 \mathrm{~mm} \mathrm{Hg}$ ); HCV, hepatitis C virus; SA-RI, intraparenchymal splenic artery resistance index; SMA-PI, superior mesenteric artery-pulsatility index; RRA-RI, right interlobar renal artery resistance index.

*Damping index=minimum velocity/maximum velocity of the hepatic vein waveform. 
ratio, portal vein/hepatic artery strength ratio, and portal vein/ hepatic artery wash-in perfusion slope ratio have close correlation with portal pressure. ${ }^{29}$

\section{Diagnostic ability for portal hypertension}

Three studies reported the actual diagnostic value of contrast parameters for the severity of portal hypertension (Table 2). The first two studies, both from South Korea, used hepatic transit time as a contrast parameter. A study by Kim et al..$^{30}$ reported that the sensitivity, specificity, positive predictive value (PPV), negative predictive value (NPV), positive likelihood ratios (PLR), negative likelihood ratios (NLR), and area under the receiver operating curve (AUROC) of transit time from the venous access to the hepatic vein (hepatic vein arrival time, HVAT) using SonoVue (cutoff value, 14 seconds) were 92.7\%, 86.7\%, 90.5\%, $89.7 \%, 6.95,0.08$, and 0.973 , respectively, on the prediction of CSPH in compensated cirrhosis. The next study compared the two parameters using SonoVue, HVAT, and intrahepatic transit time in 53 cirrhosis patients. Both showed significant differences between patients $<12 \mathrm{~mm} \mathrm{Hg}$ and those $\geq 12 \mathrm{~mm} \mathrm{Hg}$; however, the diagnostic abilities were higher in the latter (sensitivity, 85.3\%; specificity, 91.2\%; AUROC, 0.94) than in the former (sensitivity, 58.1\%; specificity, 62.8\%; AUROC, 0.72). ${ }^{31}$ The last study focused on the splenic circulation (i.e., the traveling time of microbubbles from splenic artery to splenic vein). ${ }^{32}$ The AUROC was 0.76 for CSPH with best cutoff value of 13.5 seconds and 0.76 for SPH with best cutoff value of 14.5 seconds.

\section{Subharmonic imaging}

The subharmonic mode is a novel technique using a characteristic property of microbubble. An early study in canines reported the possibility of a subharmonic aided pressure estimation (SHAPE) in the estimation of portal pressure. ${ }^{33}$ The same group examined the clinical effect of the technique in human subjects and found a good overall agreement $(\mathrm{r}=0.82)$ between the SHAPE gradient (the portal and hepatic veins) and HVPG. ${ }^{34}$ The diagnostic abilities of the SHAPE were 89\% sensitivity and 88\% specificity for patients with CSPH and 100\% sensitivity and $81 \%$ specificity for patients with $\mathrm{SPH}$. These data suggest the potential of this novel parameter as a noninvasive marker for the severity of portal hypertension.

\section{ELASTOGRAPHY}

\section{Transient elastography for liver stiffness}

Although the original application of transient elastography (TE) was assessing the fibrosis grade in the liver, recent studies have expanded the use of TE to evaluate potential liver function, severity of portal hypertension, and risk of cancer development. ${ }^{1,10,35}$

A significant relationship between the HVPG and liver stiffness (LS) by TE has been reported, ${ }^{36}$ and its actual diagnostic ability may be acceptable because the AUROC is $\geq 0.8,{ }^{37-43}$ except for two studies showing an AUROC of 0.76 and 0.78 (Ta-

Table 2. Comparison of Diagnostic Abilities in Contrast Parameters for Grading Portal Hypertension

\begin{tabular}{|c|c|c|c|c|c|c|c|}
\hline $\begin{array}{l}\text { Contrast } \\
\text { agent }\end{array}$ & $\begin{array}{l}\text { Patients, } \\
\text { no. }\end{array}$ & $\begin{array}{l}\text { Parameter } \\
\text { (cutoff value) }\end{array}$ & Reliability* & Grade of PH & $\mathrm{Se} / \mathrm{Sp} / \mathrm{PPV} / \mathrm{NPV} / \mathrm{Ac} / \mathrm{PLR} / \mathrm{NLR}$ & AUROC & Study \\
\hline \multirow[t]{2}{*}{ Sonovue } & 71 & HVAT (14 s) & $3.7 \%-3.9 \%, 2.7 \%-3.2 \%$ & $\mathrm{CSPH}$ & 93/87/91/90/-/6.95/0.08 & 0.973 & Kim et al. $^{30}$ \\
\hline & $35\left(\mathrm{v}^{\dagger}\right)$ & & $\kappa=0.87$ & & & 0.953 & \\
\hline \multirow[t]{4}{*}{ SonoVue } & 53 & HVAT (19 s) & 0.938 (ICC) & SPH & $56 / 89 / 95 / 35 / 63 /-/-, \mathrm{R}^{\ddagger}$ & 0.72 & Jeong et $a .^{31}$ \\
\hline & & & & & $\left(50 / 89 / 94 / 32 / 58 /-/-, R^{\ddagger}\right)$ & 0.71 & \\
\hline & & ITT (6 s) & 0.860 (ICC) & SPH & 91/89/97/73/91/-/-, R1 ${ }^{\ddagger}$ & 0.94 & \\
\hline & & & & & $\left(85 / 78 / 94 / 58 / 84 /-/-, \mathrm{R}^{\ddagger}\right)$ & 0.90 & \\
\hline \multirow[t]{2}{*}{ Sonazoid } & 91 & SA-SV $(13.5 \mathrm{~s})$ & $4.9 \%$ (IOV) & $\mathrm{CSPH}$ & 71/68/69/70/-/-/- & 0.76 & Shimada et al. ${ }^{32}$ \\
\hline & & SA-SV (14.5 s) & & SPH & 60/80/75/67/-I-I- & 0.76 & \\
\hline
\end{tabular}

The three studies show the diagnostic abilities of contrast parameters based on dynamic microbubbles for clinically significant portal hypertension (CSPH) and/or severe portal hypertension (SPH). The first study reported that hepatic vein arrival time (HVAT) showed area under the receiver operating curve (AUROC) 0.975/0.953 to diagnose CSPH; the second study compared two contrast parameters, HVAT and intrahepatic transit time (ITT) to diagnose SPH and found that ITT showed higher ability with AUROC 0.90/0.94. The third study proposed splenic circulation time using Sonazoid, and the AUROC for CSPH/SPH was 0.76 .

PH, portal hypertension; Se, sensitivity; Sp, specificity; PPV, positive predictive value; NPV, negative predictive value; Ac, accuracy; PLR, positive likelihood ratio; NLR, negative likelihood ratio; CSPH, clinically significant portal hypertension (hepatic venous pressure gradient $\geq 10 \mathrm{~mm}$ $\mathrm{Hg}$ ); ICC, intraclass correlation coefficient; SPH, severe portal hypertension (hepatic venous pressure gradient $\geq 12 \mathrm{~mm} \mathrm{Hg}$ ); SA-SV, splenic arterysplenic vein; IOV, interobserver variability.

*Reliability was presented by interobserver/intraobserver variability, $\kappa$-value, or ICC, 3.7\% and 3.9\% for day-to-day intraobserver variability in the HVAT measurement, $2.7 \%$ and $3.2 \%$ for IOV of the drawing and interpretation of the time-intensity curve. $\kappa=0.87$, IOV. ICC for the interpretation, 0.938 (95\% confidence interval, 0.894-0.964) for HVAT and 0.860 (0.769-0.917) for ITT. 4.9\% for IOV; ${ }^{\dagger}$ Validation set; ${ }^{\ddagger} \mathrm{R} 1$, reader 1 and R2, reader $2 ;{ }^{{ }^{5}}$ The interval time from the contrast onset in the splenic artery to the time to reach the maximum intensity level in the splenic vein. 
Table 3. Comparison of Diagnostic Abilities of Elastography for Grading Portal Hypertension

\begin{tabular}{|c|c|c|c|c|c|c|}
\hline Equipment & Patient no. & $\begin{array}{c}\text { Parameter } \\
\text { (cutoff value) }\end{array}$ & Grade of PH & $\mathrm{Se} / \mathrm{Sp} / \mathrm{PPV} / \mathrm{NPV} / \mathrm{Ac} / \mathrm{PLR} / \mathrm{NLR}$ & AUROC & Study \\
\hline \multirow[t]{2}{*}{$\mathrm{TE}$} & 61 (HCV) & LS (13.6 kPa) & $\mathrm{CSPH}$ & 97/92/97/92/-/13.7/0.02 & 0.99 & Vizzutti et al..$^{37}$ \\
\hline & & LS (17.6 kPa) & SPH & $94 / 81 / 86 / 91 /-/ 4.9 / 0.08$ & 0.92 & \\
\hline \multirow[t]{2}{*}{$\mathrm{TE}$} & 44 (HCV) & LS (20.5 kPa) & CSPH & 63/70/88/35/-/-/- & 0.76 & Lemoine et al. $^{44}$ \\
\hline & 48 (alcohol) & LS (34.9 kPa) & $\mathrm{CSPH}$ & $90 / 88 / 97 / 64 /-/-/-$ & 0.94 & \\
\hline $\mathrm{TE}$ & 150 & LS (21 kPa) & $\mathrm{CSPH}$ & 90/93/93/91/-/-/- & 0.945 & Bureau et al..$^{38}$ \\
\hline \multirow[t]{2}{*}{$\mathrm{TE}$} & 38 (HIV-HCV) & LS (14 kPa) & $\mathrm{CSPH}$ & 93/50/84/71/-/3.5/0.6 & 0.80 & Sánchez-Conde et al. ${ }^{39}$ \\
\hline & & LS (23 kPa) & SPH & $83 / 67 / 79 / 71 /-/ 2.5 / 0.5$ & 0.80 & \\
\hline $\mathrm{TE}$ & 95 & LS (29 kPa) & $\mathrm{CSPH}$ & $72 / 100 / 100 / 56 /-/ 0.3$ & 0.90 & Kitson et al. ${ }^{40}$ \\
\hline \multirow[t]{2}{*}{$\mathrm{TE}$} & 97 (C-P A, HCC) & LS (13.6 kPa) & $\mathrm{CSPH}$ & $91 / 57 / 59 / 90 /-/ 2.13 / 0.16$ & - & Llop et $a .^{36}$ \\
\hline & & LS (21 kPa) & $\mathrm{CSPH}$ & $53 / 91 / 81 / 74 /-/ 6.24 / 0.51$ & - & \\
\hline TE & 79 & LS (65.3 kPa) & $\mathrm{CSPH}$ & $52 / 100 / 100 / 21 / 57 /-/-$ & 0.78 & Elkrief et al. ${ }^{41}$ \\
\hline RT-SWE & & LS (24.5 kPa) & $\mathrm{CSPH}$ & 81/88/98/35/82/-/- & 0.87 & Elkrief et al. ${ }^{41}$ \\
\hline \multirow[t]{2}{*}{ RT-SWE } & 92 & LS (15.2 kPa) & $\mathrm{CSPH}$ & 86/80/96/52/85/-/- & 0.819 & Kim et $\mathrm{al}^{42}$ \\
\hline & & LS (21.6 kPa) & SPH & 83/81/92/66/83/-/- & 0.867 & \\
\hline $\mathrm{TE}$ & $124(\mathrm{HCV})$ & LS (8.74 kPa) & $\mathrm{HVPG}>6 \mathrm{~mm} \mathrm{Hg}$ & $90 / 81 /-/-/ 85 /-/-$ & 0.93 & Carrión et $a{ }^{43}$ \\
\hline
\end{tabular}

Table 3 summarizes the diagnostic abilities of elastography for grading portal hypertension. Transient elastography (TE) showed area under the receiver operating curve (AUROC) 0.76-0.99 for clinically significant portal hypertension (CSPH) and 0.80/0.92 for severe portal hypertension (SPH), and real-time share wave elastography (RT-SWE) showed AUROC 0.819/0.87 for CSPH and 0.867 for SPH.

PH, portal hypertension; Se, sensitivity; Sp, specificity; PPV, positive predictive value; NPV, negative predictive value; Ac, accuracy; PLR, positive likelihood ratio; NLR, negative likelihood ratio; HCV, hepatitis C virus; LS, liver stiffness; CSPH, clinically significant portal hypertension (hepatic venous pressure gradient [HVPG] $\geq 10 \mathrm{~mm} \mathrm{Hg}$ ); $\mathrm{SPH}$, severe portal hypertension (HVPG $\geq 12 \mathrm{~mm} \mathrm{Hg}$ ); HIV, human immunodeficiency virus; C-P A, Child-Pugh A.

ble 3). ${ }^{41,44}$ The accuracy of LS for SPH was significantly higher than that of Plt (platelet count)/Spl (spleen diameter) (AUROC: LS, 0.919 vs Plt/Spl, 0.828; $\mathrm{p}=0.038) .{ }^{45}$ However, some studies suggested that the linkage between LS and HVPG was dominant in mild or moderate grade portal hypertension, presented by HVPG $<10-12 \mathrm{~mm} \mathrm{Hg}$, and not in the severe grade in hepatitis C virus-related cirrhosis patients. ${ }^{37,44}$ The reasons for the poor correlation in advanced portal hypertension may be the presence of extrahepatic changes in the portal hemodynamics and the influence of various factors, such as cholestasis and inflammation, on the LS value. ${ }^{46}$

The diagnostic ability by LS for EV was summarized in Table 4; even for large EV, the AUROC remains 0.75 to $0.87 .^{38,47,48}$ These poor abilities are supported by a recent meta-analysis study: 87\% sensitivity and 53\% specificity for EV and 86\% sensitivity and 59\% specificity for large EV. ${ }^{49}$ Because of this insufficient ability, particularly poor specificity, replacement of endoscopy by TE alone may not be presently encouraged.

Recently, two studies focused on the other practical use of LS value, that is, the prediction of complications caused by portal hypertension. According to the study by Kitson et al., ${ }^{40}$ although LS >29 $\mathrm{kPa}$ was effective to identify CSPH, the prediction of complications related to portal hypertension showed 100\% sensitivity with only $40 \%$ specificity. Meanwhile, the optimal cutoff value of $34.5 \mathrm{kPa}$ provided $75.0 \%$ sensitivity, 69.4\% specificity, 52.5\% PPV, 86.2\% NPV, PLR 2.5, and NLR 0.36 for the predic- tion of complications. Furthermore, a study in 100 patients (mean follow-up period, 491 days) with chronic liver disease has shown that LS is as effective as HVPG in predicting clinical decompensation and complications caused by portal hypertension. $^{50}$

Although the waveform patterns in the hepatic vein show a close relationship with the severity of liver disease, the underlying mechanism for various patterns had been undetermined. A study by Sekimoto et al. ${ }^{51}$ reported the linkage between waveform patterns and LS, which may be a major pathogenesis to determine the waveform patterns in the hepatic vein.

\section{TE combined with other factors}

The addition of other factors may increase the diagnostic performance of TE. The AUROC of LS and Liver stiffness, spleen size, and platelet count (LSxspleen size/platelet count) for CSPH was 0.883 and 0.918 in the training set and 0.901 and 0.906 in the validation set, respectively. ${ }^{52}$ Another study also reported that combining LS with platelet count improved diagnostic accuracy in the exclusion of CSPH; an LS $>29.0 \mathrm{kPa}$ predicted CSPH with 71.9\% sensitivity, 100\% specificity, 100\% PPV, and 56.0\% NPV. An LS $<25.0 \mathrm{kPa}$ in those with platelet count $>150 \times 10^{9} / \mathrm{L}$ excluded CSPH with $91.7 \%$ sensitivity, 100\% specificity, 100\% PPV, and 90\% NPV. ${ }^{40}$

As for the diagnosis of gastroesophageal varices, a combined model with LS and platelet count was more accurate for exclud- 
ing the presence of high-risk gastroesophageal varices than either alone (training cohort AUROC: 0.87 [0.77-0.96] vs 0.78 [0.65-0.92] for LS and 0.71 [0.52-0.90] for platelets) with the combination of LS $\leq 25 \mathrm{kPa}$ and platelets $\geq 100$ having an NPV of $100 \%$ in both the training and validation cohorts. ${ }^{53}$ However, a more recent study performed in 219 alcoholic cirrhosis patients showed that none of the noninvasive tests, including aspartate aminotransferase-to-platelet ratio index, FIB-4, Forns index, Lok index, (platelet count $)^{2} /($ monocyte fraction $[\%] \times$ segmented neutrophil fraction [\%]), and platelet count to spleen diameter ratio showed reliable performance (AUROCs of all investigated tests $<0.70$ ). ${ }^{54}$ According to the study by Procopet et al., ${ }^{55}$ the use of artificial neural networks integrating different noninvasive tests did not increase the diagnostic accuracy of LS alone, which was the best way to assess the presence of cirrhosis, portal hypertension, and EV. Thus, the combined effect depends on the parameters, and further investigation may be required to seek better markers, particularly for the diagnosis and grading of EV.

\section{Reliability in the TE measurement}

It is generally believed that LS values obtained by TE are considered reliable with the traditional criteria, valid measurements of 10 times or more, a success rate $>60 \%,{ }^{56,57}$ and a quotient of interquartile range per median (IQR/M) $<0.30 .^{58}$ However, LS data are affected by several factors: $\mathrm{sex}^{59}{ }^{59}$ levels of aminotransferases, ${ }^{60,61}$ histological inflammation, ${ }^{62,63}$ extrahepatic cholestasis, ${ }^{64,65}$ liver steatosis, ${ }^{39,66,67}$ body mass index, ${ }^{68,69}$ fasting state, ${ }^{70,71}$ and central venous pressure. ${ }^{72}$ Therefore, further improvement of reliability is clearly required in TE measurement, and indeed, some studies have indicated problems in the traditional criteria and suggested room for improvement. ${ }^{69,73-75}$

Boursier et al. ${ }^{76}$ proposed new reliability criteria: "very reliable" (IQR/M $\leq 0.10)$, "reliable" $(0.10<\mathrm{IQR} / \mathrm{M} \leq 0.30$, or $\mathrm{IQR} /$ $\mathrm{M}>0.30$ with LS median<7.1 $\mathrm{kPa}$ ), and "poorly reliable" (IQR/ $\mathrm{M}>0.30$ with LS median $\geq 7.1 \mathrm{kPa}$ ). A more recent study compared traditional and new TE quality criteria (very reliable by $\mathrm{IQR} / \mathrm{M}<0.1$, and reliable by $\mathrm{IQR}<0.3$ or $>0.3$, if $\mathrm{TE}<7.1 \mathrm{kPa}$ )

Table 4. Diagnostic Ability of Elastography for Esophageal Varices

\begin{tabular}{|c|c|c|c|c|c|c|c|c|}
\hline Study & $\begin{array}{c}\text { Patient } \\
\text { no. }\end{array}$ & Etiology & $\begin{array}{c}\text { Prevalence of } \\
\text { EV (\%) }\end{array}$ & AUROC & Accuracy & Cutoff & $\mathrm{Se} / \mathrm{Sp} / \mathrm{PPV} / \mathrm{NPV}$ & Endpoint \\
\hline \multicolumn{9}{|l|}{ Liver stiffness by TE } \\
\hline Vizzutti et al. ${ }^{37}$ & 61 & $\mathrm{HCV}$ & 63.7 & 0.76 & 90 & 17.6 & $90 / 43 / 77 / 66$ & Any EV \\
\hline \multirow[t]{2}{*}{ Kazemi et al. ${ }^{47}$} & 165 & Mix & 41.2 & 0.84 & - & 13.9 & $95 / 43 / 57 / 91$ & Any EV \\
\hline & & & & 0.83 & - & 19 & $91 / 60 / 48 / 95$ & Large EV \\
\hline \multirow[t]{2}{*}{ Bureau et al. ${ }^{38}$} & 150 & Mix & 72 & 0.85 & NA & 21.1 & $84 / 71 /-/-$ & Any EV \\
\hline & & Mix & 48 & 0.76 & NA & 29.3 & $81 / 61 /-/-$ & Large EV \\
\hline \multirow[t]{2}{*}{ Castéra et al. ${ }^{48}$} & 298 & $\mathrm{HCV}$ & 36 & 0.84 & - & 21.5 & $76 / 78 / 68 / 84$ & Any EV \\
\hline & & & 19 & 0.87 & - & 30.5 & $77 / 85 / 56 / 94$ & Large EV \\
\hline \multirow[t]{2}{*}{ Pritchett et al. ${ }^{77}$} & 211 & Mix & 62.6 (mild) & 0.74 & - & 19.5 & $76 / 66 / 82 / 56$ & Any EV \\
\hline & & & 37.4, large & 0.76 & - & 19.8 & $91 / 56 / 55 / 91$ & Large (vs small) \\
\hline Nguyen-Khac et al. ${ }^{78}$ & 183 & Mix & 22.4, large & 0.75 & - & 48 & 73.2/73.2/44.1/90.4 & Large EV \\
\hline Malik et al. ${ }^{79}$ & 124 & Mix & 50.8 (in cirrhosis) & 0.85 & NA & 20 & $-/-/ 80 / 75$ & Any EV \\
\hline \multicolumn{9}{|l|}{ Liver stiffness by ARFI } \\
\hline \multirow[t]{2}{*}{ Morishita et al. ${ }^{80}$} & 135 & $\mathrm{HCV}$ & 51.1 & 0.89 & - & $2.05 \mathrm{~m} / \mathrm{s}$ & $83 / 76 / 78 / 81$ & Any EV \\
\hline & & & 33.7 & 0.868 & - & $2.39 \mathrm{~m} / \mathrm{s}$ & $81 / 82 / 69 / 89$ & Large EV \\
\hline \multicolumn{9}{|l|}{ Spleen stiffness } \\
\hline \multirow[t]{2}{*}{ Sharma et al. ${ }^{81}$} & 174 & Mix & 71 & 0.898 & 86 & $40.8 \mathrm{kPa}$ & $94 / 76 / 91 / 84$ & Any EV \\
\hline & & & & 0.819 & - & $54.5 \mathrm{kPa}$ & $76 / 73 /-/-$ & Bleeder \\
\hline Colecchia et al. ${ }^{45}$ & 100 & $\mathrm{HCV}$ & 53 & 0.941 & & & & Any EV \\
\hline \multicolumn{9}{|l|}{ Spleen stiffness by ARFI } \\
\hline \multirow[t]{2}{*}{ Takuma et al. ${ }^{82}$} & 340 & Mix & 38.8 & 0.933 & 75 & 3.18 & $98.5 / 60.1 / 61 / 98.4$ & Any EV \\
\hline & & & & 0.93 & 72.1 & 3.3 & 98.9/62.9/47.8/99.4 & Large EV \\
\hline
\end{tabular}

The diagnostic ability of liver/spleen stiffness measurement for esophageal varices (EV) is summarized. Liver stiffness measurement showed area under the receiver operating curve (AUROC) 0.74-0.89 for a presence of EV and 0.75-0.87 for large varices. Spleen stiffness measurement showed AUROC 0.898-0.941 to detect a presence of EV, which was greater than that based on liver stiffness measurement.

Se, sensitivity; Sp, specificity; PPV, positive predictive value; NPV, negative predictive value; TE, transient elastography; HCV, hepatitis C virus; NA, not available; ARFI, acoustic radiation force impulse imaging. 
regarding their diagnostic accuracy for cirrhosis and portal hypertension $^{83}$ and found that the latter increases the number of patients with accurate measurements without affecting diagnostic performance for detecting cirrhosis and portal hypertension.

\section{Acoustic radiation force impulse and share wave elastography}

Acoustic radiation force impulse (ARFI) and share wave elastography (SWE) are modalities using US-based impulse instead of mechanical impulse for TE. An early study reported an increase of share wave velocity in parallel with the increase of the splenic index $(\rho=0.409, p<0.01)$ and splenoportal index $(\rho=0.451$, $\mathrm{p}<0.01)^{84}$

In the study by Morishita et al., ${ }^{80}$ AUROC values for the presence of EV and high-risk EVs by ARFI were 0.890 and 0.868 , respectively, which had the highest diagnostic performance among factors, including serum fibrosis markers (Table 4). The diagnostic accuracy of LS by ARFI was comparable to TE and Fibrotest for the detection of complications in patients with cirrhosis. ${ }^{85}$ As for the portal pressure, data obtained by SWE (SuperSonic) showed significant correlation with the HVPG and feasibility to estimate the change in HVPG due to the medication by non-selective $\beta$-blocker in patients with portal hypertension. $^{86}$

Another issue is the lack of reliability criteria for the measurement of real-time SWE. A recent study demonstrated that standard deviation/median $\leq 10$ and/or depth $<5.6 \mathrm{~cm}$ are considered reliable criteria in the assessment of $\mathrm{CSPH}^{87}$

\section{Spleen stiffness}

Spleen is another target of elasticity measurement, and investigators have shown the benefits of spleen stiffness (SS) measurement. Two studies reported significant correlations between SS and HVPG, with SS ( $\mathrm{r}=0.433, \mathrm{p}=0.001)$, but not with LS $(r=0.178, p=0.20)$ by Sharma et $a l^{81}$ and with SS ( $r=0.885$, $\mathrm{p}=0.0001)$ and LS $(\mathrm{r}=0.836, \mathrm{p}=0.0001) .^{45}$ In fact, SS appears to provide better diagnostic performances for detecting EV compared to other noninvasive markers (Table 4).

Prospective comparison of SS and LS by using SWE and TE for detection of portal hypertension in cirrhosis was conducted by Elkrief et al. ${ }^{41}$ In patients with advanced cirrhosis who are undergoing HVPG measurements, LS measurements obtained by using SWE have a higher technical success rate and a better diagnostic value than TE for CSPH. A more recent study has shown that SS can noninvasively assess changes in portal pressure after liver transplantation and decreases significantly when portal hypertension resolves. $^{88}$

As expected, a combination of LS with SS may be effective to predict the severity of portal hypertension; the accuracy to predict significant EV was $69.6 \%$ to $70.8 \%$ using the formula with both LS and SS “ $-0.572+0.041 \times$ LS $(\mathrm{m} / \mathrm{s})+0.122 \times \mathrm{SS}(\mathrm{m} / \mathrm{s})+$ $0.325 \times$ ascites (1, absent; 2, present)." ${ }^{89}$

\section{CHALLENGES AND FUTURE DIRECTIONS}

Strength/advantage and weakness/disadvantage of various US-based techniques are summarized in Table 5. Against their apparent benefits, there are still some limitations in each modality.

Table 5. Summary of Ultrasound-Based Techniques

\begin{tabular}{|c|c|c|c|}
\hline & Application & Strength/advantage & Weakness/disadvantage \\
\hline \multicolumn{4}{|l|}{ Ultrasound } \\
\hline B-mode & First line approach & Simple and noninvasive & Available only anatomical information \\
\hline Doppler (pulsed, color, power) & $\begin{array}{l}\text { Flow direction and velocity } \\
\text { measurement }\end{array}$ & Real-time observation & $\begin{array}{l}\text { Poor detection of slow blood flow } \\
\text { Reduced frame rate }\end{array}$ \\
\hline Contrast & $\begin{array}{l}\text { Second line approach } \\
\text { Focal hepatic lesions (detection, } \\
\text { characterization, therapeutic support) } \\
\text { Diffuse liver disease (characterization, } \\
\text { grading fibrosis and portal } \\
\text { hypertension) }\end{array}$ & $\begin{array}{l}\text { Increased detectability of } \\
\text { blood flow } \\
\text { Kupffer imaging (Sonazoid) }\end{array}$ & $\begin{array}{l}\text { Invasiveness (agent injection) } \\
\text { Possible adverse events } \\
\text { Limited availability of agents } \\
\text { Cost }\end{array}$ \\
\hline Transient elastography & $\begin{array}{l}\text { Grading fibrosis and portal hypertension } \\
\text { Evaluation of complication }\end{array}$ & Simple and noninvasive & $\begin{array}{l}\text { No grey-scale image } \\
\text { Low technical success in patients with } \\
\text { ascites }\end{array}$ \\
\hline Share wave elastography & $\begin{array}{l}\text { Grading fibrosis and portal hypertension } \\
\text { Evaluation of complication }\end{array}$ & $\begin{array}{l}\text { Simple and noninvasive } \\
\text { Available grey-scale image } \\
\text { Technical success in patients } \\
\text { with ascites }\end{array}$ & Small number of research \\
\hline
\end{tabular}


Unfortunately, the diagnostic ability of Doppler parameters for portal hypertension is unsatisfactory, making the clinical application limited, and therefore alternative parameters are required with a hard/software development.

As for the contrast-enhanced US, the major problem is the limited availability of contrast agents and still, there is no available agents in some countries. Next is that because the dynamics and metabolism of in vivo microbubble have not been fully examined, the interpretation of contrast findings needs further investigation.

An establishment of reliability criteria and an improved assessment for patients with unreliable data should be considered in the field of elastography.

And finally, noninvasive diagnosis of EV is facing poor diagnostic performance. There are still challenges in the research field, suggesting our future directions for the improvement of diagnostic ability by achieving the international study with large patient population.

\section{CONCLUSIONS}

The present review article clearly demonstrates various benefits of US in the assessment of portal hypertension. Because of a close relationship with impaired portal hemodynamics, Doppler measurement data are useful to understand the underlying pathogenesis in the portal system. However, as the currently available parameters are not definitive indicator for HVPG, continuous efforts are required to determine the appropriate Doppler markers.

As for contrast-enhanced US, quantitative evaluation of microbubble behavior allows comprehensive assessment of portal hemodynamics, resulting in the efficient prediction of severity of portal hypertension.

Elastography may have an advantage of simplicity and reproducibility over Doppler/contrast mode and shows improved diagnostic ability to estimate the severity of portal hypertension. Moreover, recent studies suggest that multiple factor-based combined parameters are superior to a single modality-based parameter in the diagnostic performance.

It is expected that further development of technology (hardware and software) would make the role of US dominant in the current IVR-based diagnosis and grading of portal hypertension.

\section{CONFLICTS OF INTEREST}

No potential conflict of interest relevant to this article was reported.

\section{REFERENCES}

1. Kim MY, Jeong WK, Baik SK. Invasive and non-invasive diagnosis of cirrhosis and portal hypertension. World J Gastroenterol
$2014 ; 20: 4300-4315$.

2. Tsochatzis EA, Bosch J, Burroughs AK. Liver cirrhosis. Lancet 2014;383:1749-1761.

3. Maruyama H, Sanyal AJ. Portal hypertension: non-surgical and surgical management. In: Schiff ER, Maddrey WC, Sorrell MF, eds. Schiff's diseases of the liver. 11th ed. Oxford: Wiley-Blackwell, 2012:326-360.

4. Baik SK. Haemodynamic evaluation by Doppler ultrasonography in patients with portal hypertension: a review. Liver Int 2010;30:1403-1413.

5. Maruyama H, Kamezaki H, Kondo T, et al. Effects of inferior mesenteric vein flow in patients withcirrhosis. Clin Gastroenterol Hepatol 2013;11:1648-1654.

6. Maruyama H, Kondo T, Kiyono S, Sekimoto T, Takahashi M, Yokosuka 0. Influence of splenorenal shunt on long-term outcomes in cirrhosis. Scand J Gastroenterol 2015;50:593-600.

7. Sanyal AJ, Bosch J, Blei A, Arroyo V. Portal hypertension and its complications. Gastroenterology 2008;134:1715-1728.

8. Maruyama H, Yokosuka O. Pathophysiology of portal hypertension and esophageal varices. Int J Hepatol 2012;2012:895787.

9. D’Amico G, Garcia-Tsao G, Pagliaro L. Natural history and prognostic indicators of survival in cirrhosis: a systematic review of 118 studies. J Hepatol 2006;44:217-231.

10. Thabut D, Moreau R, Lebrec D. Noninvasive assessment of portal hypertension in patients with cirrhosis. Hepatology 2011;53:683694

11. Maruyama H, Shiha G, Yokosuka 0, et al. Non-invasive assessment of portal hypertension and liver fibrosis using contrastenhanced ultrasonography. Hepatol Int 2016;10:267-276.

12. Oberti F, Valsesia E, Pilette C, et al. Noninvasive diagnosis of hepatic fibrosis or cirrhosis. Gastroenterology 1997;113:1609-1616.

13. Colli A, Fraquelli M, Andreoletti M, Marino B, Zuccoli E, Conte D. Severe liver fibrosis or cirrhosis: accuracy of US for detection: analysis of 300 cases. Radiology 2003;227:89-94.

14. Maruyama H, Kondo T, Sekimoto T, Yokosuka O. Differential clinical impact of ascites in cirrhosis and idiopathic portal hypertension. Medicine (Baltimore) 2015;94:e1056.

15. Kondo T, Maruyama H, Sekimoto T, et al. Influence of paraumbilical vein patency on the portal hemodynamics of patients with cirrhosis. J Clin Gastroenterol 2014;48:178-183.

16. Maruyama H, Kamezaki H, Kondo T, Sekimoto T, Takahashi M, Yokosuka 0. Sonographic and clinical features of collateral vessels at the splenic hilum in cirrhosis. Clin Radiol 2014;69:e140-e145.

17. Kondo T, Maruyama H, Sekimoto T, Shimada T, Takahashi M, Yokosuka 0. Reversed portal flow: clinical influence on the longterm outcomes in cirrhosis. World J Gastroenterol 2015;21:88948902.

18. Sudhamshu KC, Matsutani S, Maruyama H, Akiike T, Saisho H. Doppler study of hepatic vein in cirrhotic patients: correlation with liver dysfunction and hepatic hemodynamics. World J Gastroenterol 2006;12:5853-5858.

19. Kondo T, Maruyama H, Sekimoto T, et al. Impact of portal hemo- 
dynamics on Doppler ultrasonography for predicting decompensation and long-term outcomes in patients with cirrhosis. Scand J Gastroenterol 2016;51:236-244.

20. Kim MY, Baik SK, Park DH, et al. Damping index of Doppler hepatic vein waveform to assess the severity of portal hypertension and response to propranolol in liver cirrhosis: a prospective nonrandomized study. Liver Int 2007;27:1103-1110.

21. Vizzutti F, Arena U, Rega L, et al. Performance of Doppler ultrasound in the prediction of severe portal hypertension in hepatitis C virus-related chronic liver disease. Liver Int 2007;27:1379-1388.

22. Berzigotti A, Gilabert R, Abraldes JG, et al. Noninvasive prediction of clinically significant portal hypertension and esophageal varices in patients with compensated liver cirrhosis. Am J Gastroenterol 2008;103:1159-1167.

23. Quaia E. Microbubble ultrasound contrast agents: an update. Eur Radiol 2007;17:1995-2008.

24. Bouakaz A, de Jong N. WFUMB Safety Symposium on EchoContrast Agents: nature and types of ultrasound contrast agents. Ultrasound Med Biol 2007;33:187-196.

25. Claudon M, Dietrich CF, Choi BI, et al. Guidelines and good clinical practice recommendations for contrast enhanced ultrasound (CEUS) in the liver-update 2012: a WFUMB-EFSUMB initiative in cooperation with representatives of AFSUMB, AIUM, ASUM, FLAUS and ICUS. Ultrasound Med Biol 2013;39:187-210.

26. Maruyama H, Sekimoto T, Yokosuka 0. Role of contrast-enhanced ultrasonography with Sonazoid for hepatocellular carcinoma: evidence from a 10-year experience. J Gastroenterol 2016;51:421433.

27. Zhang CX, Hu J, Hu KW, Zhang C, Wang L, Xu JM. Noninvasive analysis of portal pressure by contrast-enhanced sonography in patients with cirrhosis. J Ultrasound Med 2011;30:205-211.

28. Berzigotti A, Nicolau C, Bellot P, et al. Evaluation of regional hepatic perfusion (RHP) by contrast-enhanced ultrasound in patients with cirrhosis. J Hepatol 2011;55:307-314.

29. Qu EZ, Zhang YC, Li ZY, Liu Y, Wang JR. Contrast-enhanced sonography for quantitative assessment of portal hypertension in patients with liver cirrhosis. J Ultrasound Med 2014;33:19711977.

30. Kim MY, Suk KT, Baik SK, et al. Hepatic vein arrival time as assessed by contrast-enhanced ultrasonography is useful for the assessment of portal hypertension in compensated cirrhosis. Hepatology 2012;56:1053-1062.

31. Jeong WK, Kim TY, Sohn JH, Kim Y, Kim J. Severe portal hypertension in cirrhosis: evaluation of perfusion parameters with contrast-enhanced ultrasonography. PLoS One 2015;10:e0121601.

32. Shimada T, Maruyama H, Kondo T, Sekimoto T, Takahashi M, Yokosuka 0. Impact of splenic circulation: non-invasive microbubble-based assessment of portal hemodynamics. Eur Radiol 2015;25:812-820.

33. Dave JK, Halldorsdottir VG, Eisenbrey JR, et al. Investigating the efficacy of subharmonic aided pressure estimation for portal vein pressures and portal hypertension monitoring. Ultrasound Med
Biol 2012;38:1784-1798.

34. Eisenbrey JR, Dave JK, Halldorsdottir VG, et al. Chronic liver disease: noninvasive subharmonic aided pressure estimation of hepatic venous pressure gradient. Radiology 2013;268:581-588.

35. Castera L, Pinzani M, Bosch J. Non invasive evaluation of portal hypertension using transient elastography. J Hepatol 2012;56:696703.

36. Llop E, Berzigotti A, Reig M, et al. Assessment of portal hypertension by transient elastography in patients with compensated cirrhosis and potentially resectable liver tumors. J Hepatol 2012;56:103108.

37. Vizzutti F, Arena U, Romanelli RG, et al. Liver stiffness measurement predicts severe portal hypertension in patients with HCVrelated cirrhosis. Hepatology 2007;45:1290-1297.

38. Bureau C, Metivier S, Peron JM, et al. Transient elastography accurately predicts presence of significant portal hypertension in patients with chronic liver disease. Aliment Pharmacol Ther 2008;27:1261-1268.

39. Sánchez-Conde M, Montes Ramírez ML, Bellón Cano JM, et al. Impact of liver steatosis on the correlation between liver stiffness and fibrosis measured by transient elastography in patients coinfected with human immunodeficiency virus and hepatitis $\mathrm{C}$ virus. J Viral Hepat 2011;18:e278-e283.

40. Kitson MT, Roberts SK, Colman JC, Paul E, Button P, Kemp W. Liver stiffness and the prediction of clinically significant portal hypertension and portal hypertensive complications. Scand J Gastroenterol 2015;50:462-469.

41. Elkrief L, Rautou PE, Ronot M, et al. Prospective comparison of spleen and liver stiffness by using shear-wave and transient elastography for detection of portal hypertension in cirrhosis. Radiology 2015;275:589-598.

42. Kim TY, Jeong WK, Sohn JH, Kim J, Kim MY, Kim Y. Evaluation of portal hypertension by real-time shear wave elastography in cirrhotic patients. Liver Int 2015;35:2416-2424.

43. Carrión JA, Navasa M, Bosch J, Bruguera M, Gilabert R, Forns X. Transient elastography for diagnosis of advanced fibrosis and portal hypertension in patients with hepatitis $\mathrm{C}$ recurrence after liver transplantation. Liver Transpl 2006;12:1791-1798.

44. Lemoine M, Katsahian S, Ziol M, et al. Liver stiffness measurement as a predictive tool of clinically significant portal hypertension in patients with compensated hepatitis C virus or alcohol-related cirrhosis. Aliment Pharmacol Ther 2008;28:1102-1110.

45. Colecchia A, Montrone L, Scaioli E, et al. Measurement of spleen stiffness to evaluate portal hypertension and the presence of esophageal varices in patients with HCV-related cirrhosis. Gastroenterology 2012;143:646-654.

46. Mueller S, Sandrin L. Liver stiffness: a novel parameter for the diagnosis of liver disease. Hepat Med 2010;2:49-67.

47. Kazemi F, Kettaneh A, N'kontchou G, et al. Liver stiffness measurement selects patients with cirrhosis at risk of bearing large oesophageal varices. J Hepatol 2006;45:230-235.

48. Castéra L, Le Bail B, Roudot-Thoraval F, et al. Early detection in 
routine clinical practice of cirrhosis and oesophageal varices in chronic hepatitis C: comparison of transient elastography (FibroScan) with standard laboratory tests and non-invasive scores. J Hepatol 2009;50:59-68.

49. Shi KQ, Fan YC, Pan ZZ, et al. Transient elastography: a metaanalysis of diagnostic accuracy in evaluation of portal hypertension in chronic liver disease. Liver Int 2013;33:62-71.

50. Robic MA, Procopet B, Métivier S, et al. Liver stiffness accurately predicts portal hypertension related complications in patients with chronic liver disease: a prospective study. J Hepatol 2011;55:10171024.

51. Sekimoto T, Maruyama H, Kiyono S, et al. Liver stiffness: a significant relationship with the waveform pattern in the hepatic vein. Ultrasound Med Biol 2015;41:1801-1807.

52. Berzigotti A, Seijo S, Arena U, et al. Elastography, spleen size, and platelet count identify portal hypertension in patients with compensated cirrhosis. Gastroenterology 2013;144:102-111.e1.

53. Ding NS, Nguyen T, Iser DM, et al. Liver stiffness plus platelet count can be used to exclude high-risk oesophageal varices. Liver Int 2016;36:240-245.

54. Cho EJ, Kim MY, Lee JH, et al. Diagnostic and prognostic values of noninvasive predictors of portal hypertension in patients with alcoholic cirrhosis. PLoS One 2015;10:e0133935.

55. Procopet B, Cristea VM, Robic MA, et al. Serum tests, liver stiffness and artificial neural networks for diagnosing cirrhosis and portal hypertension. Dig Liver Dis 2015;47:411-416.

56. Ziol M, Handra-Luca A, Kettaneh A, et al. Noninvasive assessment of liver fibrosis by measurement of stiffness in patients with chronic hepatitis C. Hepatology 2005;41:48-54.

57. Castéra L, Vergniol J, Foucher J, et al. Prospective comparison of transient elastography, Fibrotest, APRI, and liver biopsy for the assessment of fibrosis in chronic hepatitis C. Gastroenterology 2005;128:343-350.

58. Fraquelli M, Rigamonti C, Casazza G, et al. Reproducibility of transient elastography in the evaluation of liver fibrosis in patients with chronic liver disease. Gut 2007;56:968-973.

59. Roulot D, Czernichow S, Le Clésiau H, Costes JL, Vergnaud AC, Beaugrand M. Liver stiffness values in apparently healthy subjects: influence of gender and metabolic syndrome. J Hepatol 2008;48:606-613.

60. Coco B, Oliveri F, Maina AM, et al. Transient elastography: a new surrogate marker of liver fibrosis influenced by major changes of transaminases. J Viral Hepat 2007;14:360-369.

61. Chan HL, Wong GL, Choi PC, et al. Alanine aminotransferasebased algorithms of liver stiffness measurement by transient elastography (Fibroscan) for liver fibrosis in chronic hepatitis B. J Viral Hepat 2009;16:36-44.

62. Lupşor M, Badea R, Stefãnescu H, et al. Analysis of histopathological changes that influence liver stiffness in chronic hepatitis C: results from a cohort of 324 patients. J Gastrointestin Liver Dis 2008;17:155-163.

63. Arena U, Vizzutti F, Abraldes JG, et al. Reliability of transient elastography for the diagnosis of advanced fibrosis in chronic hepatitis C. Gut 2008;57:1288-1293.

64. Millonig G, Reimann FM, Friedrich S, et al. Extrahepatic cholestasis increases liver stiffness (FibroScan) irrespective of fibrosis. Hepatology 2008;48:1718-1723.

65. Harata M, Hashimoto S, Kawabe N, et al. Liver stiffness in extrahepatic cholestasis correlates positively with bilirubin and negatively with alanine aminotransferase. Hepatol Res 2011;41:423429.

66. Lupsor M, Badea R, Stefanescu H, et al. Performance of unidimensional transient elastography in staging non-alcoholic steatohepatitis. J Gastrointestin Liver Dis 2010;19:53-60.

67. Boursier J, de Ledinghen V, Sturm N, et al. Precise evaluation of liver histology by computerized morphometry shows that steatosis influences liver stiffness measured by transient elastography in chronic hepatitis C. J Gastroenterol 2014;49:527-537.

68. Das K, Sarkar R, Ahmed SM, et al. "Normal" liver stiffness measure (LSM) values are higher in both lean and obese individuals: a population-based study from a developing country. Hepatology 2012;55:584-593.

69. Myers RP, Crotty P, Pomier-Layrargues G, Ma M, Urbanski SJ, Elkashab M. Prevalence, risk factors and causes of discordance in fibrosis staging by transient elastography and liver biopsy. Liver Int 2010;30:1471-1480.

70. Berzigotti A, De Gottardi A, Vukotic R, et al. Effect of meal ingestion on liver stiffness in patients with cirrhosis and portal hypertension. PLoS One 2013;8:e58742.

71. Arena U, Lupsor Platon M, Stasi C, et al. Liver stiffness is influenced by a standardized meal in patients with chronic hepatitis $\mathrm{C}$ virus at different stages of fibrotic evolution. Hepatology 2013;58:65-72

72. Millonig G, Friedrich S, Adolf S, et al. Liver stiffness is directly influenced by central venous pressure. J Hepatol 2010;52:206-210.

73. Castéra L, Foucher J, Bernard PH, et al. Pitfalls of liver stiffness measurement: a 5-year prospective study of 13,369 examinations. Hepatology 2010;51:828-835.

74. Sirli R, Sporea I, Bota S, Jurchiş A. Factors influencing reliability of liver stiffness measurements using transient elastography (Mprobe)-monocentric experience. Eur J Radiol 2013;82:e313-e316.

75. Lucidarme D, Foucher J, Le Bail B, et al. Factors of accuracy of transient elastography (fibroscan) for the diagnosis of liver fibrosis in chronic hepatitis C. Hepatology 2009;49:1083-1089.

76. Boursier J, Zarski JP, de Ledinghen V, et al. Determination of reliability criteria for liver stiffness evaluation by transient elastography. Hepatology 2013;57:1182-1191.

77. Pritchett S, Cardenas A, Manning D, Curry M, Afdhal NH. The optimal cut-off for predicting large oesophageal varices using transient elastography is disease specific. J Viral Hepat 2011;18:e75e80.

78. Nguyen-Khac E, Saint-Leger P, Tramier B, Coevoet H, Capron D, Dupas JL. Noninvasive diagnosis of large esophageal varices by Fibroscan: strong influence of the cirrhosis etiology. Alcohol Clin 
Exp Res 2010;34:1146-1153.

79. Malik R, Lai M, Sadiq A, et al. Comparison of transient elastography, serum markers and clinical signs for the diagnosis of compensated cirrhosis. J Gastroenterol Hepatol 2010;25:1562-1568.

80. Morishita N, Hiramatsu N, Oze T, et al. Liver stiffness measurement by acoustic radiation force impulse is useful in predicting the presence of esophageal varices or high-risk esophageal varices among patients with HCV-related cirrhosis. J Gastroenterol 2014;49:11751182.

81. Sharma P, Kirnake V, Tyagi P, et al. Spleen stiffness in patients with cirrhosis in predicting esophageal varices. Am J Gastroenterol 2013;108:1101-1107.

82. Takuma Y, Nouso K, Morimoto Y, et al. Measurement of spleen stiffness by acoustic radiation force impulse imaging identifies cirrhotic patients with esophageal varices. Gastroenterology 2013;144:92-101.e2.

83. Schwabl P, Bota S, Salzl P, et al. New reliability criteria for transient elastography increase the number of accurate measurements for screening of cirrhosis and portal hypertension. Liver Int 2015;35:381-390.
84. Han JY, Cho JH, Kwon HJ, Nam KJ. Predicting portal hypertension as assessed by acoustic radiation force impulse: correlations with the Doppler ultrasound. Br J Radiol 2012;85:e404-e409.

85. Vermehren J, Polta A, Zimmermann 0, et al. Comparison of acoustic radiation force impulse imaging with transient elastography for the detection of complications in patients with cirrhosis. Liver Int 2012;32:852-858.

86. Choi SY, Jeong WK, Kim Y, Kim J, Kim TY, Sohn JH. Shear-wave elastography: a noninvasive tool for monitoring changing hepatic venous pressure gradients in patients with cirrhosis. Radiology 2014;273:917-926.

87. Procopet B, Berzigotti A, Abraldes JG, et al. Real-time shear-wave elastography: applicability, reliability and accuracy for clinically significant portal hypertension. J Hepatol 2015;62:1068-1075.

88. Chin JL, Chan G, Ryan JD, McCormick PA. Spleen stiffness can non-invasively assess resolution of portal hypertension after liver transplantation. Liver Int 2015;35:518-523.

89. Bota S, Sporea I, Sirli R, et al. Can ARFI elastography predict the presence of significant esophageal varices in newly diagnosed cirrhotic patients? Ann Hepatol 2012;11:519-525. 